\title{
Dynamic Panel Data Model for Investment, Real Value and Capital Stock Data
}

\author{
G. R. Pasha \\ Department of Statistics \\ Bahauddin Zakariya University \\ Multan, Pakistan \\ E-mail: drpasha@bzu.edu.pk \\ Muhammad Aslam \\ Department of Statistics \\ Bahauddin Zakariya University \\ Multan, Pakistan \\ E-mail: aslamasadi@bzu.edu.pk \\ Muhammad Abdullah \\ Department of Statistics \\ Bahauddin Zakariya University \\ Multan, Pakistan \\ mambk@brain.net.pk
}

\begin{abstract}
Panel data modeling is being used increasingly as a versatile tool to study various economic relationships. In such studies, sometimes, the dependent variable depends not only on the pure exogenous variables, but also on its own lag values. This intervention leads us to use dynamic panel data models. While using least squares dummy variable estimator, we show the attractive performance of such models as compared to that of simple panel data models. The choice of dynamic panel data model brings salient results in terms of lower standard error of regression, improvement in $R^{2}$ and right specification of the model.
\end{abstract}

Keywords: Capital stock; Dummy variable; Dynamic Model: Dynamic Panel Data model; Investment; Least squares dummy variable; Panel data; Real value.

\section{Introduction}

To find an adequately fitted model for an economical phenomenon has been a great intension of researchers since very ancient times. The functional form and the different methods of estimation of a classical model are main and powerful sources to satisfy this intension. In the way, panel data model is an attempt of the same type. Panel data refers to a cross-section repeatedly sampled over time, but where the same economic agent has been followed throughout the period of the sample. A number of studies can be found in the favour of panel data modeling, for example, see Hsiao (1986), Judson and Owen (1996), Nerlove (2000) and Baltagi, (2001), etc. among many others.

The panel data models are themselves well explanatory, when we encounter the data on a set of economic units observed at more than one point in time. But it is very often that the response variable depends not only on pure exogenous 
variables but also its own lag values. In this paper, we have compared the different characteristics of dynamic panel data models and the simple panel data model while dealing with the example of real gross investment depending upon real value and capital stock.

In Section 2, we explain fixed effect panel data model and its estimation by LSDV estimator. In Section 3, we describe the formulation of dynamic panel data model. In Section 4, the applications of dynamic panel data model is illustrated with the help of example and comparison are made between simple and dynamic panel data models while Section 5 concludes.

\section{Fixed Effect Panel Data Models (FEM)}

Consider a simple linear regression model, which can be used to charactersise behaviour in a panel: A panel data regression, in general known as fixed effect panel data model, has the function as

$$
y_{i t}=\alpha+X_{i t}^{\prime} \beta+u_{i t} \quad i=1,2, \ldots, N ; t=1,2, \ldots ., T
$$

with $i$ denoting individuals, firms, countries, etc. and $t$ denoting time. The subscript $i$, therefore, denote the cross-section dimension whereas $t$ denotes the time series dimension, $\alpha$ is a scalar, $\beta$ is a $K \times 1$ and $X_{i t}$ is the itth observation on $K$ explanatory variables.

\subsection{The Least Squares Dummy Variable (LSDV) Estimator}

Under this approach of estimation of (2.1), it is assumed that any differences across economic agents can be captured by shifts in the intercept term of a standard OLS regression. This leads to the least square dummy variable (LSDV) estimator of a fixed effects regression model. The LSDV model can be estimated by defining a series of group-specific dummy variables $d_{\text {git }}=1(g=i)$. In terms of (2.1), this gives

$$
\begin{aligned}
y_{i t} & =\alpha_{i}+X_{i t}^{\prime} \beta+u_{i t} \\
& =\alpha_{1} d_{1 i t}+\alpha_{2} d_{2 i t}+\cdots+\alpha_{N} d_{N i t}+X_{i t}^{\prime} \beta+u_{i t}
\end{aligned}
$$

This model is easily estimated by standard OLS over the full panel to yield the LSDV estimator.

\section{Dynamic Panel Data Model}

For a long time, the long run growth phenomenon of different macro-economical variables for panels of different countries has engaged the attention of social and behavioral science researchers (see, e.g., Levine and Renelt, 1992). In different economic relationships, the dependent variable depends not only on the pure exogenous variables, but also on its own lag values. These relationships are called dynamic in nature. The panel data model that allows to observe this dynamics of adjustment is referred as dynamic panel data model. A limited economical literature is available on this issue (see for example, Arellano and Bond, 1991; Ziliak, 1997; Baltagi, 2001). 
The general functional form of dynamic panel data model is as:

$$
y_{i t}=\alpha+\delta y_{i, t-1}+X_{i t}^{\prime} \beta+u_{i t} \quad i=1,2, \ldots, N ; t=1,2, \ldots ., T
$$

where $\alpha$ and $\delta$ are scalars, $\beta$ is a $K \times 1$ and $X_{i t}^{\prime}$ is $(1 \times K)$ the $i$ th observation on $K$ explanatory variables.

Arellano and Bond (1991) reported that LSDV estimator can be used for models like (3.1) provided that $N$ is small.

\section{Applications}

For illustration and application of dynamic panel data model, we take the data, as quoted by Gujarati (2003, Pp 639), to investigate the dependence of real gross investment $(Y)$ on real value of the firm $\left(X_{1}\right)$ and real capital stock $\left(X_{2}\right)$. The data are about four companies for the period 1935-1954. Therefore there are 4 crosssectional units and 20 time periods i.e, $N=4, T=20$.

Firstly, we estimate the FEM (2.1) for these data with the help of LSDV estimator. In order to capture the dynamic effect, we add the lag variable of real gross investment in the list of exogenous variables and resultantly, we use the model like (3.1). Again, we estimate this model by LSDV estimator.

The estimated model like (2.1) for the said data is;

$$
\hat{Y}_{t}=-271.14+0.117 X_{1}+0.351 X_{2}+348.69 D_{1}+141.83 D_{2}+202.76 D_{3}
$$

The estimated dynamic panel data model is;

$$
\begin{aligned}
& \hat{Y}_{t}=-226.36+0.619 Y_{t-1}+0.106 X_{1}+0.151 X_{2}+136.33 D_{1}-65.18 D_{2}+158.02 \\
& D_{3}
\end{aligned}
$$

It is to be noted that coefficient of $Y_{t-1}$ is highly significant in this model showing $p$-value approaching to zero and justifying the adoption of dynamic model in this situation.

Table 4.1 presents the comparison between the both models on the basis of standard errors of the estimated coefficients. Since in (4.2), we have introduced an additional lag variable so there is no need to compare the standard errors of the regression coefficients and they are given in the said table just for the information.

Table 4.2 gives the comparison between the two different models on the basis of standard error of regression, Akaike information criteria (AIC) value, Schwarz information criteria (SIC) value, adjusted $R^{2}$ and the Durban-Watson (DW) statistic for autocorrelation. We note that the standard error of regression is considerably smaller for dynamic panel data model which shows the less spread of estimated values around the true values. Improvement in $R^{2}$ and adjusted $R^{2}$ 
can also be noted with the inclusion of lag dependent variable in the list of exogenous variables.

The lower values of AIC and SIC for the dynamic model justify the use of such model in this case and thus, showing the right specification of the model. Furthermore, the value of the Durbin-Watson d-statistic for non-dynamic modeling falls in positive correlation region, whereas the value for dynamic modeling lies in inconclusive region. Though, it is an inconclusive situation, but it is more preferable than the positive correlation.

Table 4.1: Estimated coefficients and Standard Errors

\begin{tabular}{|c|c|c|c|c|}
\hline \multirow{2}{*}{ Predictor } & \multicolumn{2}{|c|}{$\begin{array}{c}\text { LSDV Non-dynamic } \\
\text { Modeling }\end{array}$} & \multicolumn{2}{c|}{$\begin{array}{c}\text { LSDV Dynamic } \\
\text { Modeling }\end{array}$} \\
\cline { 2 - 5 } & Coefficients & S.E & Coefficients & S.E \\
\hline Constant & -271.140 & 38.500 & -226.360 & 31.330 \\
\hline$Y_{t-1}$ & --- & --- & 0.619 & 0.095 \\
\hline$X_{1}$ & 0.116 & 0.018 & 0.106 & 0.015 \\
\hline$X_{2}$ & 0.351 & 0.027 & 0.151 & 0.038 \\
\hline$D_{1}$ & 348.690 & 24.470 & 136.330 & 38.050 \\
\hline$D_{2}$ & 141.830 & 49.001 & -65.180 & 50.300 \\
\hline$D_{3}$ & 202.760 & 33.040 & 158.020 & 27.110 \\
\hline
\end{tabular}

Table 4.2: Comparison Summary between Simple and Dynamic Panel Data Model

\begin{tabular}{|l|c|c|}
\hline Computations & $\begin{array}{c}\text { LSDV Non-dynamic } \\
\text { Modeling }\end{array}$ & $\begin{array}{c}\text { LSDV Dynamic } \\
\text { Modeling }\end{array}$ \\
\hline SE of Estimate (S) & 74.88 & 59.44 \\
\hline R-Square & $93.7 \%$ & $96.1 \%$ \\
\hline R-Square (adj) & $93.3 \%$ & $95.8 \%$ \\
\hline AIC & 5588.964 & 3470.617 \\
\hline SIC & 6127.559 & 3805.073 \\
\hline $\begin{array}{l}\text { Durbin-Watson } \\
\text { d-statistic }\end{array}$ & 0.96 & 1.61 \\
$(\mathrm{~d}=1.49, \mathrm{du}=1.77)$ & $(\mathrm{dl}=1.46, \mathrm{du}=1.80)$ \\
\hline
\end{tabular}

\section{Conclusion}

When we investigate the dependence of real investment on real value and capital stock, we should also see the impact of the past values of the investments. This leads us to the use of dynamic panel data model if we are treating with panel data. We further conclude, while dealing with fixed effect panel data models, that if the past values of the dependent variable also exert their effects then it is better to use dynamic panel data model rather than simple or non-dynamic panel model. The choice of dynamic panel data model brings attractive results in terms of lower standard error of regression, improvement in $R^{2}$ and correction for autocorrelation. 


\section{References}

1. Arellano, M. and Bond, S. (1991). Some Tests of Specification for Panel Data: Monte Carlo Evidence and an Application to Employment Equations. Review of Economic Studies, 58, 277-297.

2. Baltagi, B. H. (2001). Econometric Analysis of Panel Data. John Wiley and Sons Ltd, Chichester, England.

3. Gujarati, D. N. (2003). Basic Econometrics. McGraw Hill, New York, 638640.

4. Hsiao, C. (1986). Analysis of Panel Data. Cambridge University Press, Cambridge.

5. Judson, R. A. and Owen, A. L. (1996). Estimating Dynamic Panel Data Models: A Practical Guide for Macroeconomists. Economic Letters, 65, 915.

6. Levine, R. and Renelt, D. (1992). A sensitivity analysis of Cross-Country Growth Regressions. American Economic Review, 942-63.

7. Nerlove, M. (2000). An Essay on the History of Panel Data Econometrics", Proceedings of Ninth International Conference on Panel Data, Geneva, Switzerland.

8. Ziliak, J. P. (1997). Efficient Estimation with Panel Data when Instruments are Predetermined: An Empirical Comparison of Moment Condition Estimators. Journal of Business and Economics Statistics, 15, 419-431. 